\title{
Prova de Conceito e Análise de Desempenho em Protótipo de Sistema para o Tratamento Natural de Efluentes Domésticos
}

Proof of Concept and Performance Analysis in a Prototype System for Natural Treatment of Domestic Sewage

\section{Resumo}

Esse artigo apresenta a concepção, o processo de desenvolvimento e os resultados operacionais iniciais do projeto de um sistema energeticamente eficiente e de baixo custo para o tratamento natural de efluentes domésticos. $\bigcirc$ objetivo do projeto era o de desenvolver um sistema para o tratamento, reuso e a reciclagem da água consumida em um típico domicílio brasileiro, que usa os próprios micro-organismos encontrados nos efluentes no processo, sem demanda de aditivos químicos. O sistema é projetado para funcionar com baixo custo operacional, de manutenção e de consumo energético. Como método, foi empregada uma versão simplificada da proposição de Ulrich e Eppinger (2015) para o desenvolvimento de novos produtos, avançando até a fase de testes e refinamentos. Iniciado em 2015, o projeto atualmente já concluiu as primeiras etapas do desenvolvimento, possuindo um protótipo funcional capaz de tratar cerca de quatro mil litros de efluentes por dia, com resultados promissores comprovados por meio de análises laboratoriais. Como resultados, tanto o desempenho individual de cada módulo, assim como também o desempenho global do sistema, são apresentados e discutidos à luz do planejamento e das especificações iniciais. $\bigcirc$ artigo é concluído argumentando-se que o sistema é promissor, constituindo-se numa efetiva prova de conceito para o projeto

\section{Abstract}

This article presents the design, development process and initial operational results of an energy efficient and low-cost system for the natural treatment of domestic effluents. The objective of the project is to develop a system for the treatment, reuse and recycling of water consumed in a typical Brazilian household, which uses the microorganisms found in the effluents in the process, without the need for chemical additives. The system is designed to operate with low-cost, low-maintenance and low-energy consumption. As a method, a simplified version of the proposition of Ulrich and Eppinger (2015) was used, advancing to the testing and refinement phase. Started in 2015 , the project has now completed the first stages of development, with a functional prototype capable of treating about 4,000 liters of effluent per day, with promising results proven through laboratory analysis. As a result, both the individual performance of each module as well as overall system performance are presented and discussed in the light of initial planning and specifications. The article is concluded by arguing that the system is promising, constituting an effective proof of concept for the project.

Keywords:
Palavras-chave: tratamento; efluentes domés

ticos; baixo custo; projeto do produto; sistema cost; product design and development; system;

\footnotetext{
Rua Miguel de Frias, 9, Icaraí, Niterói - RJ, CEP: 24220-900, ramon_narcizo@id.uff.br; 2. antonisio@gmail.com; 3. rodolfo.cardoso@ lei.uff.br; 4. iaratammela@vm.uff.br; 5. henriquemadeira@id.uff.br. NARCIZO, R. B.; MARTINS, A. P.; CARDOSO, R.; TAMMELA, I., MADEIRA, H. S. Prova de Conceito e Análise de Desempenho em Protótipo de Sistema para o Tratamento Natural de Efluentes Domésticos. GEPROS. Gestão da Produção, Operações e Sistemas, v. 14, n.3, p. 59 - 72, 2019

DOI: 10.15675/gepros.v74i3.2602
} 


\section{INTRODUÇÃO}

O acesso ao saneamento básico é um fator crítico para a qualidade da vida humana, uma vez que sua indisponibilidade contribui para o surgimento de problemas de saúde na população (LEONETI et al., 2011). Segundo a Pesquisa Nacional de Saneamento Básico (referente ao ano de 2008), a proporção de municípios com rede de coleta de esgoto é inferior à de municípios com rede geral de distribuição de água, manejo de resíduos sólidos e de águas pluviais. Ainda de acordo com a pesquisa, $55 \%$ dos municípios brasileiros possuem rede coletora de esgoto sendo que apenas $29 \%$ do total de municípios tratam o esgoto coletado. O descarte de esgoto sem tratamento na natureza, pode ocasionar diversos impactos ambientais e sociais, como desequilíbrios em ecossistemas aquáticos e a transmissão de doenças por meio de águas contaminadas (IBGE, 2010).

Numa escala global, as taxas de crescimento populacional e de consumo dos recursos naturais implicam em significativos impactos ao planeta, dos quais a natureza demonstra sinais de não conseguir regenerar-se na mesma velocidade (MANZINI, 2008). Considerando o contínuo agravamento dessa situação desde os anos 50 do Séc. XX, em 1992 aconteceu na cidade do Rio de Janeiro a Eco-92, onde representantes de 108 países se reuniram para discutir medidas para diminuir a degradação ambiental e garantir a o futuro de outras gerações (NOVAES, 1992). A partir dessa conferência, difundiu-se o conceito de 'ecoeficiência', como uma abordagem precursora da sustentabilidade. Esse conceito engloba, dentre outros elementos fundamentais, a proposta de minimizar a intensidade energética e de recursos empregados na produção de bens e serviços, além de fomentar a reciclabilidade materiais e componentes (ANTELLO, 2015; FERREIRA; VIOLA, 1996).

Considerando essas perspectivas e tendências, uma equipe multidisciplinar de desenvolvimento composta por engenheiros, professores universitários, empresários e inventores independentes - tem trabalhado desde 2015 em um projeto focado na criação de um sistema energeticamente eficiente e de baixo custo para o tratamento natural de efluentes domésticos. O objetivo do projeto é desenvolver um sistema capaz de funcionar com baixo custo operacional, de manutenção e de consumo energético, integrando os conceitos de 'sistemas emergentes' (JOHNSON, 2003), 'inovação aberta' (CHESBROUGH, 2006) e 'projeto berço-a-berço' (MCDONOUGH; BRAUNGART, 2002).

Operacionalmente, trata-se de um sistema concebido para o tratamento, reuso e a reciclagem da água consumida em um típico domicílio brasileiro, que usa os próprios micro-organismos encontrados nos efluentes para realizar seu tratamento, sem demanda de aditivos químicos. Atualmente, o projeto já avançou nas primeiras etapas do desenvolvimento, possuindo um protótipo funcional instalado em uma residência no município de Rio das Ostras, na Região das Baixadas Litorâneas do Estado do Rio de Janeiro. Esse protótipo, que funciona como uma 'prova de conceito' para o sistema, é capaz de tratar cerca de quatro mil litros de efluentes por dia, e já apresenta resultados promissores, 
comprovados por meio de análises laboratoriais.

Considerando o exposto, o presente artigo tem por objetivo apresentar as principais características desse projeto, incluindo a concepção do sistema, seu processo de desenvolvimento e resultados operacionais iniciais. Como método, foi empregada uma versão simplificada da proposição de Ulrich e Eppinger (2015) para o desenvolvimento de novos produtos, avançando até a fase de testes e refinamentos. Como resultados, tanto o desempenho individual de cada módulo, assim como também o desempenho global do sistema, são apresentados e discutidos à luz do planejamento e das especificações iniciais almejados. Dentre as conclusões finais, se argumenta que o sistema é promissor, e que se constitui numa efetiva prova de conceito para o projeto.

\section{REFERENCIAL TEÓRICO}

\subsection{Síntese das características dos efluentes domésticos}

A NBR 9648 preconiza que o esgoto sanitário é o "despejo líquido constituído de esgotos domésticos e industriais, água de infiltração e a contribuição pluvial parasitária”. Ainda de acordo com essa norma, esgoto doméstico é o "despejo líquido resultante do uso da água para higiene e necessidades fisiológicas humanas” (ABNT, 1986). As composições dos efluentes industriais e domésticos ou sanitários podem variar de acordo com diversos fatores. Já no caso dos efluentes domésticos o clima, a situação social e econômica e os hábitos da população são os principais responsáveis pela composição dos rejeitos. Das características físicas, a matéria solida é a de maior importância (JORDÃO; PESSÔA, 2009),

Existem cinco principais características físicas ligadas aos esgotos domésticos: matéria sólida (cerca de $0,1 \%$ do volume), temperatura, odor, cor e turbidez e variação de vazão. Cerca de $70 \%$ dos sólidos encontrados nos efluentes domésticos são de origem orgânica. Destes, proteínas e carboidratos são os principais, constituindo aproximadamente $90 \%$ dos efluentes. Ainda podem ser encontrados óleos e gorduras. O enxofre presente nas proteínas é o grande responsável pela presença de gás sulfídrico. Também é encontrada matéria inorgânica, formada principalmente por areia e minerais dissolvidos. Bactérias, fungos, protozoários, vírus e algas são os principais organismos encontrados nos esgotos domésticos. Nesse grupo, as bactérias possuem um papel importante, pois consomem a matéria orgânica presente no efluente (FUNDAÇÃO NACIONAL DE SAÚDE, 2004).

Para a decisão sobre o tipo de tratamento que será dado aos efluentes, os aspectos mais relevantes são: nível de eficiência almejado; área disponível para a implantação; custo e complexidade de implantação e operação de cada processo; condicionantes ambientais relativos à localização da unidade; meios para a produção e disposição de lodos; e dependência de insumos externos. A classificação do 
tratamento de efluentes é feita em níveis de eficiência, que podem ser complementares, de modo a facilitar a execução das etapas e se obter um resultado mais satisfatório (BRASIL, 2011). Ainda de acordo com essa referência, as principais etapas do processo de tratamento de efluentes são:

- Preliminar: Remove os grandes sólidos visando evitar obstruções e corrosão das demais unidades de tratamento.

- Primário: Reduz a matéria orgânica contida no esgoto, geralmente pelo uso de unidades de sedimentação (como decantadores). Pode-se utilizar também bactérias por meio de reatores anaeróbios para decompor a matéria orgânica presente efluente.

- Secundário: Produz efluentes em conformidade com a legislação ambiental a partir da degradação biológica dos efluentes. Geralmente são utilizados tanques com grandes quantidades de micro-organismos, chamados de reatores biológicos, onde os fenômenos naturais de estabilização da matéria orgânica são reproduzidos em uma velocidade maior que a natural, e em condições controladas.

- Terciário: Remove substâncias como nitrogênio e fósforo dos efluentes, caso o tratamento na fase secundária não tenha sido capaz de atender por completo os critérios exigidos pela legislação vigente. A remoção de nitrogênio é normalmente realizada no processo de lodos ativados. Geralmente, a remoção de fósforo é realizada por meio de tratamento químico, utilizando-se sulfato de alumínio ou outro agente coagulante.

- Desinfecção: Realiza a desinfecção dos efluentes a partir da remoção de organismos patogênicos. A desinfecção total pode ser realizada por processos naturais, como por exemplo, lagoa de maturação, cloração, ozonização ou radiação ultravioleta.

De acordo com Von Sperling (1998), existem diferentes sistemas e tecnologias para o tratamento de esgotos, sendo os mais importantes e tradicionais no Brasil: lagoas de estabilização; disposição dos efluentes no solo; reatores anaeróbios; sistemas de lodos ativados; e reatores aeróbios com biofilme. Segundo Jordão e Pessôa (2009), no tratamento de efluentes os indicadores de qualidade possuem relação com o projeto, a operação, as exigências legais e a avaliação de desempenho das estações de tratamento. Alguns dos principais parâmetros são: temperatura, $\mathrm{pH}$, nitrogênio, fósforo, oxigênio dissolvido, demanda bioquímica de oxigênio e demanda química de oxigênio.

\subsection{Projeto do produto e design orientado ao meio-ambiente}

O desenvolvimento de produtos pode ser entendido, segundo Clark e Fujimoto (1991), como um processo no qual uma organização transforma diversos dados e informações em oportunidades de mercado e possibilidades de produtos comerciais. Similarmente, para Ulrich e Eppinger (2012) esse 
processo compreende uma sequência de passos que uma empresa deve seguir para conceber, desenvolver e comercializar um produto.

Ulrich e Eppinger (2015) afirmam ainda que o projeto orientado ao meio-ambiente (Design For Environment - DFE) fornece métodos práticos que podem aumentar a qualidade do produto e reduzir os custos de produção, minimizando seus impactos ambientais. O consumo de energia e recursos naturais, o despejo de líquidos, a emissão de gases e a geração de resíduos sólidos são impactos ambientais de um produto e devem ser considerados no projeto. Segundo Van Hemel (1998), no Design For Environment, o meio-ambiente define a direção das decisões do projeto e tem a mesma importância que o lucro, funcionalidade, imagem e qualidade. Para o autor, esse conceito implica em considerar os aspectos ambientais em cada estágio do processo de desenvolvimento de um produto, buscando alcançar produtos que tenham o menor impacto ambiental possível em todo o seu ciclo de vida.

Por outro lado, Mcdonough e Braungart (2002) discordam das estratégias projetuais baseadas ecoeficiência, pois acreditam que não se deve focar apenas na mera redução dos impactos ecológicos e da intensidade de consumo de recursos naturais. Os autores apresentam o termo alternativo 'ecoeficácia', definindo-o como uma estratégia para a criação de uma base industrial segura, rentável e regenerativa, produzindo valor econômico, ambiental e social. Um projeto ecoeficaz vai além dos aspectos econômicos, incorporando elementos do o conceito 'berço-a-berço', como upcycling, utilização de energia renovável e adaptação ao ambiente local.

O termo ‘berço-a-berço' foi cunhado pelos autores supracitados como o projeto e a produção de produtos que ao final de seu ciclo de vida possam ser integralmente reciclados usando a mesma lógica dos recursos na natureza, ou seja, como nutrientes completamente seguros, não-tóxicos e biodegradáveis. Nessa abordagem os produtos devem ser compostos tanto por materiais biodegradáveis, que alimentam ciclos biológicos, quanto por materiais técnicos, que são integralmente reaproveitados num ciclo fechado, circulando como nutrientes valiosos para uma indústria. Essa visão é baseada em três princípios: eliminação do conceito de desperdício; utilização de energia renovável; e respeito à diversidade humana e natural dos sistemas. Portanto, a escolha de materiais é crucial para as fases iniciais do projeto do produto, porém a utilização de energias sustentáveis e a adaptação ao ambiente local - natureza, economia, cultura e sociedade - são conceitos fundamentais para o sucesso da implementação dessa abordagem (MCDONOUGH; BRAUNGART, 2002).

\section{MÉTODO EMPREGADO PARA O DESENVOLVIMENTO DO SISTEMA}

O método empregado para o desenvolvimento do protótipo para o sistema de tratamento de efluentes foi baseado fundamentalmente nas proposições de Ulrich e Eppinger (2015), incorporando 
as orientações conceituais do "Design Total", conforme definidas por Pugh (1991). A abordagem de Ulrich e Eppinger (2015) pode ser sintetizada num método sistemático que objetiva alcançar a integração entre os aspectos tecnológicos e não-tecnológicos do desenvolvimento, viabilizando a criação bem-sucedida de produtos (bens ou serviços) e até mesmo de processos. A metodologia geralmente é representada num fluxo genérico composto por seis principais fases, a saber: (1) planejamento do projeto; (2) geração do conceito; (3) projeto em nível de sistema; (4) projeto detalhado; (5) testes e refinamentos e, por fim, (6) preparação da produção dos lotes pilotos. O Quadro 1 apresenta as descrições, principais etapas e produtos gerados para cada fase do projeto.

Quadro 1 - Principais fases e etapas do projeto

\begin{tabular}{|c|c|c|c|}
\hline Fase & Descrição & Principais etapas & Produto gerado \\
\hline $\begin{array}{l}\text { 1. Análise de } \\
\text { requisitos }\end{array}$ & $\begin{array}{l}\text { Adotando a perspectiva de } \\
\text { desenvolvimento do tipo } \\
\text { market pull (puxada pelo } \\
\text { mercado), nesta fase inicial a } \\
\text { equipe realizou uma varredura } \\
\text { sobre as oportunidades } \\
\text { econômicas, ambientais e } \\
\text { sociais vinculadas ao sistema } \\
\text { em desenvolvimento. }\end{array}$ & $\begin{array}{l}\text { 1.1. Estudos sobre sistemas naturais } \\
\text { de tratamento de efluentes. } \\
\text { 1.2. Identificação dos principais } \\
\text { requisitos técnicos, funcionais, } \\
\text { normativos e de mercado. } \\
\text { 1.3. Análise da viabilidade técnica e } \\
\text { econômica. }\end{array}$ & $\begin{array}{l}\text { Relatório } \\
\text { sintetizando as } \\
\text { informações } \\
\text { obtidas nessa fase. }\end{array}$ \\
\hline $\begin{array}{l}\text { 2. Definição } \\
\text { das } \\
\text { principais } \\
\text { especificações } \\
\text { técnicas }\end{array}$ & $\begin{array}{l}\text { Determinação de um conjunto } \\
\text { de especificações que } \\
\text { permitissem mensurar de } \\
\text { forma quantitativa os } \\
\text { parâmetros de desempenho do } \\
\text { equipamento em relação aos } \\
\text { requisitos identificados na fase } \\
\text { anterior. }\end{array}$ & $\begin{array}{l}\text { 2.1. Levantamento da documentação } \\
\text { técnica de sistemas semelhantes. } \\
\text { 2.2. Definição do escopo técnico, } \\
\text { diferenciais e funcionalidades do } \\
\text { equipamento. } \\
\text { 2.3. Definição das especificações } \\
\text { técnicas. }\end{array}$ & $\begin{array}{l}\text { Documento textual } \\
\text { sintetizando as } \\
\text { métricas e os } \\
\text { valores associados } \\
\text { às especificações } \\
\text { técnicas. }\end{array}$ \\
\hline
\end{tabular}




\begin{tabular}{|c|c|c|c|}
\hline $\begin{array}{l}\text { 3. Projeto do } \\
\text { conceito e } \\
\text { projeto em } \\
\text { nível de } \\
\text { sistema }\end{array}$ & $\begin{array}{l}\text { Elaboração, análise e teste dos } \\
\text { possíveis conceitos para o } \\
\text { equipamento. Ao final, um } \\
\text { único conceito (considerado o } \\
\text { mais promissor), ainda focado } \\
\text { em termos gerais de sua } \\
\text { arquitetura, foi projetado com } \\
\text { o auxílio de ferramentas } \\
\text { computacionais. }\end{array}$ & $\begin{array}{l}\text { 3.1. Geração de conceitos. } \\
\text { 3.2. Análise técnica dos conceitos. } \\
\text { 3.3. Seleção do conceito mais } \\
\text { promissor. } \\
\text { 3.4. Modelagem geral do conceito } \\
\text { usando ferramenta computacional. }\end{array}$ & $\begin{array}{l}\text { Modelagem 3D, } \\
\text { em termos dos } \\
\text { principais } \\
\text { componentes da } \\
\text { arquitetura, do } \\
\text { conceito } \\
\text { selecionado. }\end{array}$ \\
\hline $\begin{array}{l}\text { 4. Projeto } \\
\text { detalhado, } \\
\text { testes e } \\
\text { refinamentos }\end{array}$ & $\begin{array}{l}\text { Após o projeto conceitual, o } \\
\text { sistema foi projetado } \\
\text { detalhadamente, tendo sua } \\
\text { arquitetura desdobrada em } \\
\text { termos de módulos, e esses em } \\
\text { termos de componentes } \\
\text { individuais. Assim, ao final } \\
\text { dessa fase, todo o projeto } \\
\text { técnico necessário para a } \\
\text { construção do protótipo estava } \\
\text { concluído. }\end{array}$ & $\begin{array}{l}\text { 4.1. Projeto dos módulos. } \\
\text { 4.2. Fabricação dos componentes } \\
\text { mecânicos. } \\
\text { 4.3. Fabricação dos componentes } \\
\text { eletrônicos e de automação. } \\
\text { 4.4. Fabricação dos módulos. } \\
\text { 4.5. Testes dos módulos } \\
\text { (individualmente e em conjunto). } \\
\text { 4.6. Análises dos testes dos } \\
\text { módulos. } \\
\text { 4.7. Montagem do protótipo físico. } \\
\text { 4.8. Testes do protótipo em campo. } \\
\text { 4.9. Ajustes finais no projeto } \\
\text { técnico. }\end{array}$ & $\begin{array}{l}\text { (a) Projeto técnico } \\
\text { para fabricação do } \\
\text { protótipo } \\
\text { (documentação } \\
\text { técnica); } \\
\text { (b) Protótipo } \\
\text { funcional do } \\
\text { equipamento; e } \\
\text { (c) Relatório } \\
\text { contendo os } \\
\text { resultados dos } \\
\text { testes de } \\
\text { desempenho. }\end{array}$ \\
\hline
\end{tabular}

Fonte: Eläböração própria

As principais adaptações no método estavam relacionadas às suas fases iniciais, especialmente no que tange a identificação da oportunidade de mercado e o levantamento das demandas dos potencias usuários. Tendo em vista a premissa de que o projeto possuía um escopo orientado primariamente para a pesquisa e o desenvolvimento - com foco na construção de um primeiro protótipo para testar e validar o conceito do sistema - o método englobou apenas as cinco primeiras etapas da proposição de Ulrich e Eppinger (2015), com algumas simplificações. Assim, avançou-se até a fase de testes e refinamentos, tendo como principal saída do projeto a construção e os testes de um protótipo operacional. Isso se deveu porque os aspectos relacionados à produção em escala e às vendas não estavam incluídos no escopo do projeto. 


\section{CONSTRUÇÃO DO PROTÓTIPO, APRESENTAÇÃO E DIS- CUSSÃO DOS RESULTADOS}

A equipe responsável pelo desenvolvimento do protótipo concebeu o projeto a partir de quatro principais marcos a serem alcançados pelo equipamento. O primeiro marco, chamado de 'água segura', visa o desenvolvimento dos processos de separação mecânica, bem como os processos biológicos anaeróbios e aeróbios necessários à retirada dos poluentes e contaminantes mais perigosos do efluente. O segundo marco, chamado 'água potável', objetiva o desenvolvimento dos processos de absorção dos poluentes do efluente, empregando plantas, sistemas de filtragem e esterilização por raios ultravioleta. Esse processo deve ser capaz de produz uma água cristalina e sem odor. O terceiro marco, 'combate pesado', objetiva o desenvolvimento dos processos que garantirão a destinação final segura aos agentes poluentes. Por fim, o quarto marco trata dos 'acessórios', cujo objetivo é o desenvolvimento de diversos módulos auxiliares com funções específicas.

A construção do primeiro protótipo, cuja visão geral é apresentada na Figura 1, foi iniciada em abril de 2015 e concluída em outubro do mesmo ano. O equipamento, que custou por volta de sete mil reais para ser produzido, atualmente está funcionando em uma residência urbana habitada por quatro adultos, na cidade de Rio das Ostras (Estado do Rio de Janeiro), com capacidade operacional para o tratamento de cerca de quatro mil litros de efluentes por dia. O sistema foi concebido para possuir um total de dez módulos, responsáveis pelo tratamento do efluente e o atingimento dos quatro principais marcos do projeto.

Figura 1 - Visão geral do protótipo do sistema (real e projeto simplificado).
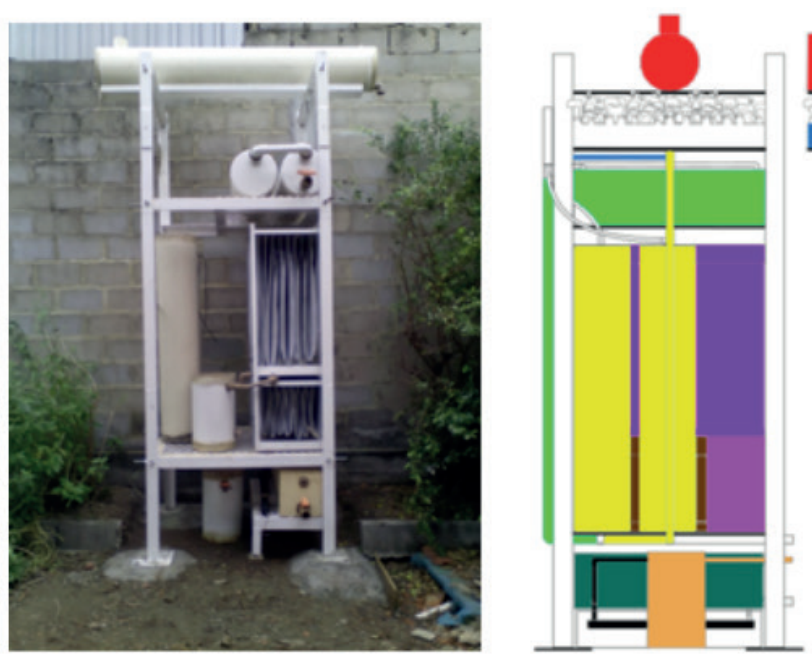

Vista Lateral Esquerda

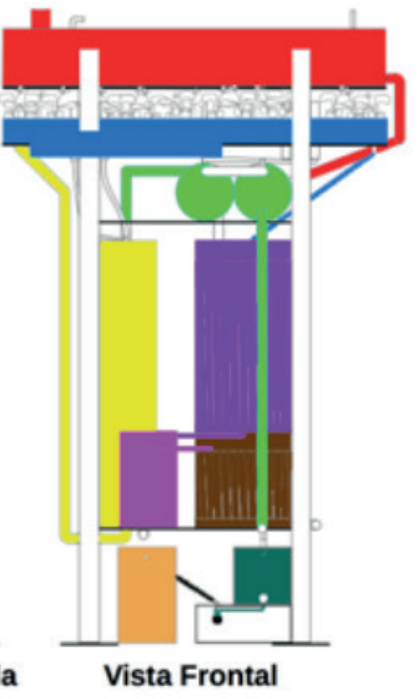

\section{Legenda}

Modulo 1 - Receptor de efluente
e unidade elevatoria
Modulo 2 - Separador por coleta
em nivels
Modulo 3 - Filtro com reaçao
anaerobia
Modulo 4 - Zona de ralzes
nodulo 5 - Reator aerobio
(tase de aeraçao)
Modulo 6 - Reator Aeróio
(fase anoxica)
Modulo 7 - Reator Aerobio
modulo 8 - Separador por tase
modulo 9 - Esterlizador por luz
ultravioleta
Modulo 10 - Filtro de particulas

Fonte: Elaboração própria 
Atualmente, sete dos dez principais módulos do sistema já estão em operação. Um esboço simplificado do projeto técnico do protótipo, com todos os módulos originalmente concebidos, também é mostrado na Figura 1. Por questões estratégicas, algumas informações técnicas sobre a arquitetura do equipamento e seu funcionamento foram intencionalmente suprimidas deste artigo. Contudo, de forma geral, o sistema opera da seguinte forma:

O Módulo 1, chamado de 'receptor de efluente e unidade elevatória', é responsável por receber o efluente em seu estado bruto. O módulo opera com vazão variável, regulando o fluxo do sistema e separando as maiores partículas do efluente de modo mecânico, por meio de gradeamento. É composto basicamente por uma unidade elevatória que bombeia o efluente para um reservatório elevado e um regulador de vasão. Isso faz com que toda a operação do sistema, a partir desse ponto, ocorra integralmente por ação da gravidade. O Módulo 2, ‘separador por coleta em níveis’ realiza a separação das partículas mais densas e menos densas que a água. Já o Módulo 3, ‘filtro com reação anaeróbia' tem por objetivo reter micro-organismos e matéria orgânica.

Ainda conforme a Figura 2, o Módulo 4, chamado de 'zona de raízes' tem por função filtrar a matéria orgânica e reduzir as cargas química e orgânica do efluente. Esse módulo emprega espécies de plantas capazes de absorver, por meio de suas raízes, diferentes substâncias nocivas contidas no efluente. O Módulo 5 'reator aeróbio (fase de aeração)' atua ativando o metabolismo aeróbio dos micro-organismos presentes no efluente. O Módulo 6, 'reator aeróbio (fase anóxica)' mantêm bactérias e matéria orgânica em suspensão e estimula o metabolismo anaeróbio desses organismos. Por fim, o Módulo 7, 'reator aeróbio', realiza a reaeração do efluente em fluxo.

Adicionalmente, cabe destacar que os demais módulos, a saber: Módulo 8, 'separador por fase' (que retém o lodo produzido nos processos anteriores); Módulo 9, 'esterilizador por luz ultravioleta' (que elimina todos os eventuais micro-organismos remanescentes no efluente); e o Módulo 10, 'filtro de partículas' (que retém mecanicamente quaisquer partículas que ainda estejam presentes na água) não foram fabricados para este protótipo, e, portanto, seus desempenhos ainda não puderam ser testados.

Após a construção do protótipo um conjunto de testes e análises preliminares teve início. Foi verificado que alguns dos módulos apresentaram resultados satisfatórios, mas a equipe de desenvolvimento percebeu a necessidade de ajustes, correções, adaptações e melhorias no projeto, visando melhorar a performance global do equipamento. Por exemplo, em relação ao Módulo 1 foi observado que sua capacidade poderia ser redimensionada de modo a evitar riscos de transbordamento do efluente em horários de alta demanda. Já o Módulo 2 apresentou o funcionamento esperado, porém ainda são necessários estudos mais aprofundados para determinar sua eficiência.

Por outro lado, outros módulos do protótipo apresentaram operações distintas das esperadas e possivelmente demandarão modificações significativas ou redesenho de seus componentes. Para alguns desses módulos, a equipe avalia que será necessário gerar novos conceitos. Testes no Módulo 
3, por exemplo, indicaram que a retenção da matéria orgânica não ocorreu como o esperado. Já no Módulo 5 verificou-se a capacidade de este desencadear a oxidação das partículas de ferro presentes no efluente, porém sua eficiência no processo de oxigenação ainda está abaixo da planejada. Os resultados do Módulo 6 ainda são inconsistentes, mas análises preliminares sugerem que deve haver uma redução da vazão na saída desse módulo, de forma que o efluente permaneça em tratamento por mais tempo e o resultado esperado seja obtido. O Módulo 7 apresentou o pior desempenho dentre os demais. Análises iniciais sugerem que a falha desse módulo esteja diretamente relacionada ao módulo anterior (reator anóxico). Contudo, ainda não foi possível chegar a uma conclusão definitiva, sendo necessários mais testes.

Tendo em vista os resultados obtidos a partir das análises preliminares, ao longo dos anos de 2016 e 2017 foram realizados novos testes e análises com o intuito de melhor compreender o funcionamento do protótipo. Os primeiros testes envolveram o monitoramento de amostras de efluentes coletados em diferentes etapas do tratamento. Já o segundo foi realizado com o intuito de observar o comportamento individual de cada um dos módulos operacionais do protótipo.

Figura 2 - Amostras retiradas do sistema de tratamento.

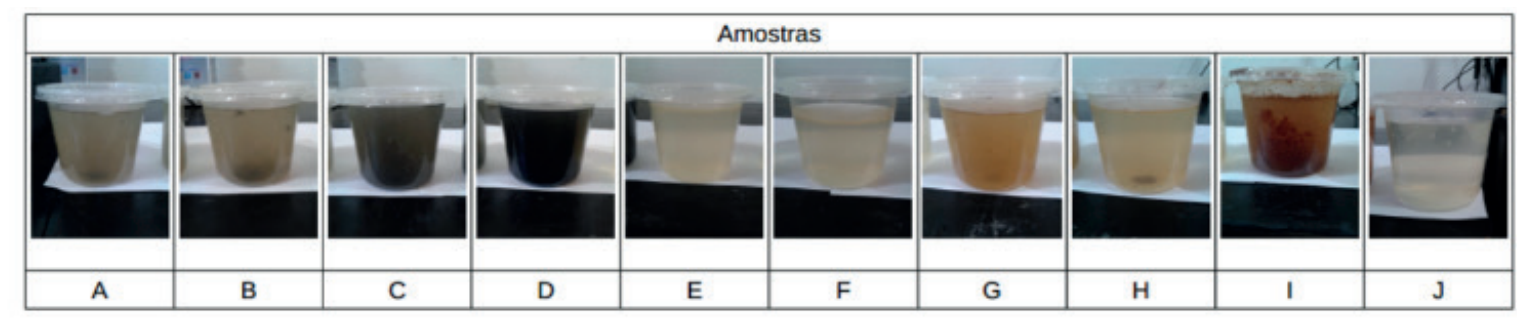

\section{Legenda}

A- Amostra do efluente bruto

B- Amostra da drenagem do separador da fase pesada

C- Amostra da drenagem do separador da fase leve

D- Amostra da drenagem do separador de matéria orgânica

E- Amostra da entrada da bandeja de gigogas

F- Amostra da saída da bandeja de gigogas

G- Amostra do fundo do reator anóxico

H- Amostra da profundidade média do reator anóxico

I- Amostra da superfície do reator anóxico

J- Amostra da saída do reaerador 


\section{Legenda}

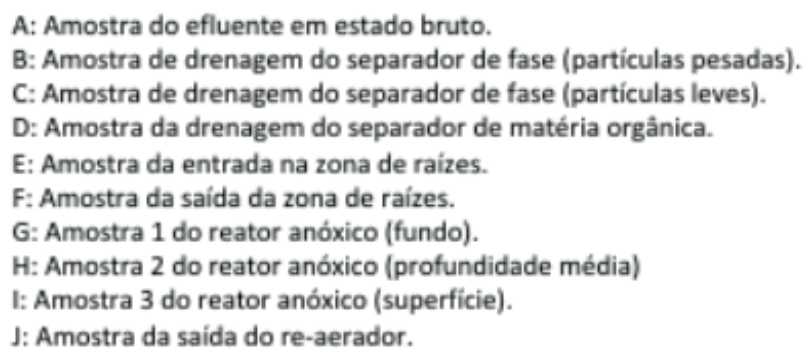

Fonte: Elaboração própria

Para o primeiro experimento, cujos resultados são ilustrados pela Figura 2, a residência na qual o protótipo está instalado foi normalmente utilizada, e a planta de tratamento operada manualmente. A ordem de coleta das amostras foi estabelecida visando minimizar a interferência do procedimento na dinâmica normal da operação do equipamento. Para isso a coleta foi feita em ordem inversa à sequência natural de tratamento. Após a coleta, a amostras foram posicionadas lado a lado, não sendo manipuladas até o fim do registro. Foram feitos seis registros de cada amostra, com intervalos de quatro horas, ao longo de um período de 24 horas.

O segundo experimento também foi feito analisando-se o comportamento natural da casa. Seu objetivo era analisar o funcionamento de cada módulo do protótipo. Uma breve síntese dos resultados obtidos nos experimentos é apresentada como segue.

- Módulo 1: Tanto a unidade elevatória quanto o reservatório elevado apresentaram o funcionamento esperado. Observou-se no reservatório um acúmulo de sedimentos no tubo no qual estavam acoplados os sensores de nível, mas esse processo não comprometeu seu desempenho.

- Módulo 2: Foi observado um vazamento, que gerou contaminação no aerador. A amostra do separador de partículas pesadas apresentou uma concentração de resíduos menor que a esperada. Supõe-se que haja um fluxo não previsto entre os separadores, capaz de reposicionar parte dos resíduos acumulados neste módulo no separador de partículas leves.

- Módulo 3: As amostras dos separadores de matéria orgânica apresentaram alta concentração, porém a retenção do material não ocorreu conforme o planejado. Esse módulo aparentemente atuou como um segundo estágio da separação por fase.

- Módulo 4: Esse módulo já passou por algumas melhorias e refinamentos, tanto em termos de projeto quanto das espécies vegetais empregadas para sua operação. Inicialmente, usou-se a Gigoga (Eichhornia) para essa função. Porém, o manejo dessa espécie revelou-se pouco prático à operação do sistema. Assim, as espécies Lentilha d'Água (Lemna sp.) e Azolla (Azolla caroliniana) estão sendo estudadas atualmente. 
- Módulo 5: Embora não tenham sido observados os sinais esperados de aerobiose nesse módulo, foi possível constatar que este é capaz de adicionar oxigênio ao efluente, ainda que de modo ineficiente. Estudos mais detalhados são necessários.

- Módulo 6: O resultado observado nesse módulo sugere que não houve tempo suficiente para o efluente reagir por completo, conforme originalmente planejado.

- Módulo 7: A amostra desse módulo não apresentou as características esperada. É possível que a falha esteja no reator anóxico, mas os resultados ainda são inconclusivos.

Posteriormente, entre 2016 e 2017, foram realizadas análises físico-químicas por meio de exames laboratoriais, com o propósito de comparar alguns dos principais parâmetros da legislação vigente com os encontrados nos resultados do protótipo. Verificou-se que o protótipo do sistema, mesmo com as ineficiências identificadas, estava próximo a produzir como saída final a chamada 'água servida tratada', conforme os padrões de lançamento de efluentes dispostos na Resolução do CONAMA N. 430.

\section{CONCLUSÕES E REFLEXÕES FINAIS}

Este artigo apresenta as principais características - incluindo a concepção, o processo de desenvolvimento e os resultados iniciais - de um protótipo para um sistema energeticamente eficiente e de baixo custo para o tratamento natural (sem aditivos químicos) de efluentes domésticos. O protótipo, que englobou sete dos dez módulos inicialmente planejados, custou cerca de R $\$ 7$ mil e foi construído por uma equipe multidisciplinar de desenvolvimento, que tem trabalhado no projeto desde 2015 na cidade de Rio das Ostras, no Estado do Rio de Janeiro.

Ainda que o equipamento tenha apresentado limitações operacionais, foi observado que esse protótipo funcionou como uma 'prova de conceito' para o sistema. Os testes laboratoriais sugerem que o equipamento, mesmo que ainda incompleto e com problemas de desempenho em alguns de seus módulos, está próximo de de produzir água em acordo com os parâmetros estabelecidos pela Resolução N. 430 do Conselho Nacional do Meio Ambiente. Esses resultados sugerem que a continuidade do projeto, em termos de desenvolvimento e melhorias, pode trazer resultados ainda mais promissores.

Como recomendações finais, em função de sua criticidade para o desempenho geral do equipamento, é sugerido que seja realizado um estudo detalhado sobre diferentes conceitos, com foco na arquitetura, para o Módulo 5 - Reator Aeróbio (fase de aeração). Além disso, também é recomendado que a equipe de desenvolvimento busque apoio financeiro e técnico para a melhoria do sistema por meio de instituições de financiamento à pesquisa e parcerias com instituições de pesquisa e desenvolvimento. 


\section{Referências}

ANTELLO, P. H. G. A situação das políticas de sustentabilidade brasileiras perante as metas de desenvolvimento do milênio da ONU no ano de 2008. Interações, v. 14, n. especial, 2015.

ASSOCIAÇÃO BRASILEIRA DE NORMAS TÉCNICAS. ABNT. NBR 9648: Estudo de concepção de sistemas de esgoto sanitário. Rio de Janeiro, 1986.

BRASIL. Resolução n. ${ }^{\circ}$ 430, de 13 de maio de 2011. Dispõe sobre as condições e padrões de lançamento de efluentes, complementa e altera a Resolução n. ${ }^{\circ}$ 357, de 17 de março de 2005, do Conselho Nacional do Meio Ambiente-CONAMA. Diário Oficial da União, 2011.

CHESBROUGH, H. W. The era of open innovation. Managing Innovation and Change, v. 127, n. 3, p. 34-41, 2006.

CLARK, K. B.; FUJIMOTO, T. Product Development Performance: Strategy, Organization, and Management in the World Auto Industry. Boston: Harvard Business School Press, 1991.

FERREIRA, L. C.; VIOLA, E. Incertezas de sustentabilidade na globalização. Campinas: Unicamp, 1996.

FUNDAÇÃO NACIONAL DE SAÚDE. Manual de Saneamento. 3 ed. Brasília: FUNASA, 2004.

INSTITUTO BRASILEIRO DE GEOGRAFIA E ESTATÍSTICA (ed.). Pesquisa nacional de saneamento básico: 2008. Rio de Janeiro: IBGE, 2010.

JOHNSON, S. Emergência: a dinâmica de rede em formigas, cérebros, cidades e softwares. Rio de Janeiro: Zahar, 2003.

JORDÃO, E. P.; PESSÔA, C. A. Tratamento de Esgotos Domésticos. 6 ed. Rio de Janeiro: ABES, 2009.

LEONETI, A. B. PRADO, E. L.; OLIVEIRA, S. V. W. B. Saneamento básico no Brasil: considerações sobre investimentos e sustentabilidade para o século XXI. Revista de Administração Pública, v. 45, n. 2 , p. 331-348, 2011. 
MANZINI, E. Design para a inovação social e sustentabilidade: comunidades criativas, organizações colaborativas e novas redes projetuais. Rio de Janeiro: E-papers, v. 200, 2008.

MCDONOUGH, W.; BRAUNGART, M. Cradle to cradle: remaking the way we make things. 1 ed. New York: North Point Press, 2002.

NOVAES, W. Eco-92: avanços e interrogações. Estudos Avançados, v. 6, n. 15, p. 79-93, ago. 1992.

PUGH, S. Total design: integrated methods for successful product engineering. 1 ed. Harlow: Pearson Education, 1991.

ULRICH, K. T.; EPPINGER, S. D. Product design and development. 6 ed. New York: McGraw-Hill Education, 2015.

VON SPERLING, M. Introdução à qualidade das águas e ao tratamento de esgotos. 2 ed. Belo Horizonte: SEGRAC, 1998. 